S. $30 \%$

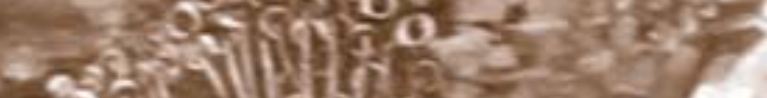

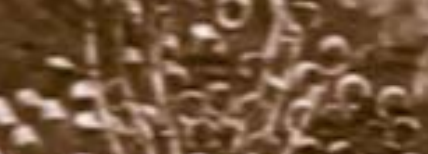

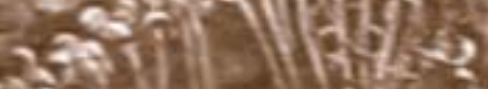

2

AP

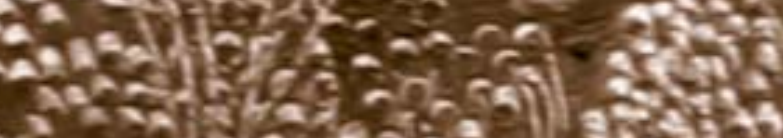

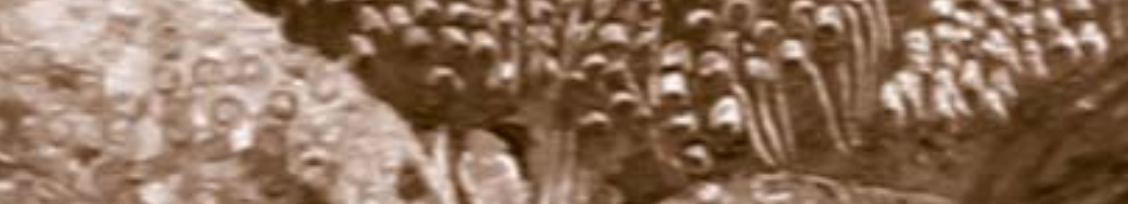

$\sin 2$
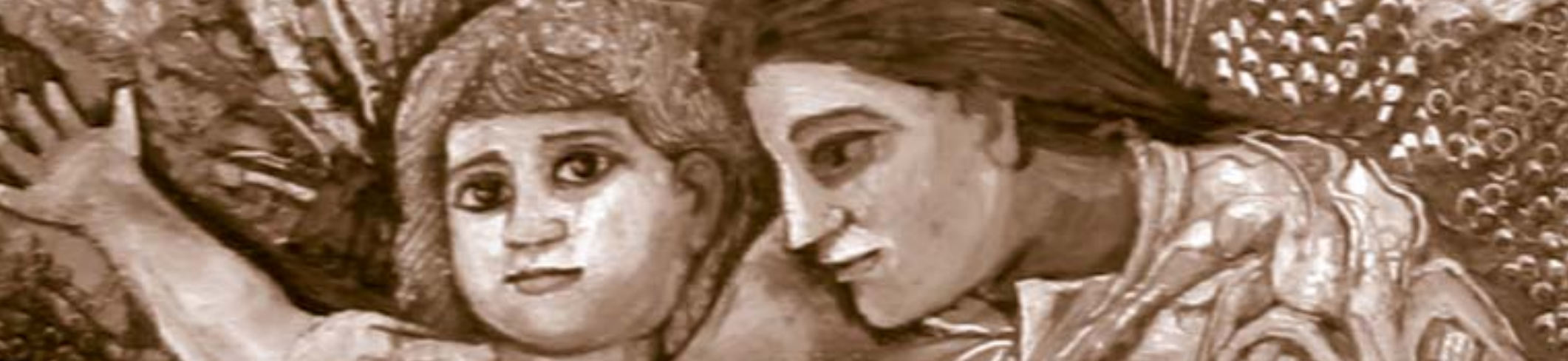

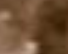

का
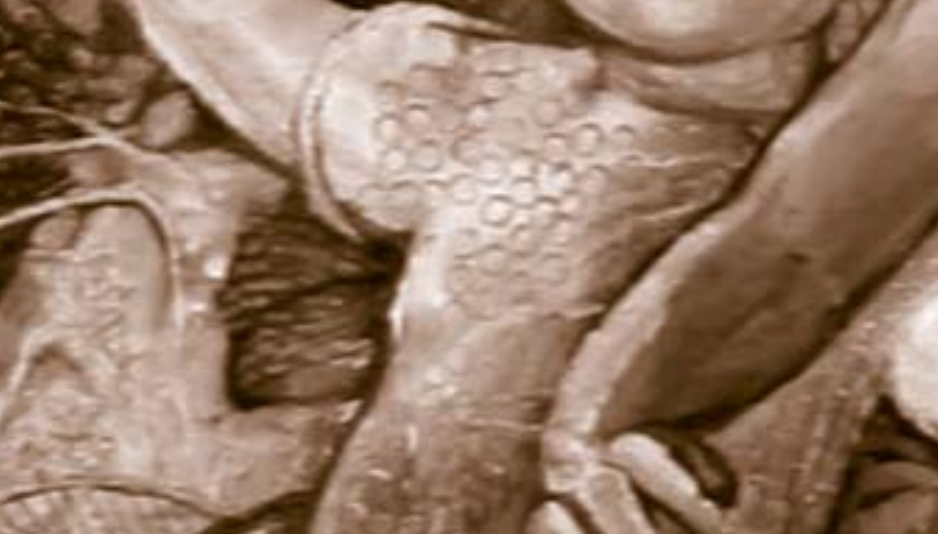

$1 \rightarrow 30219$
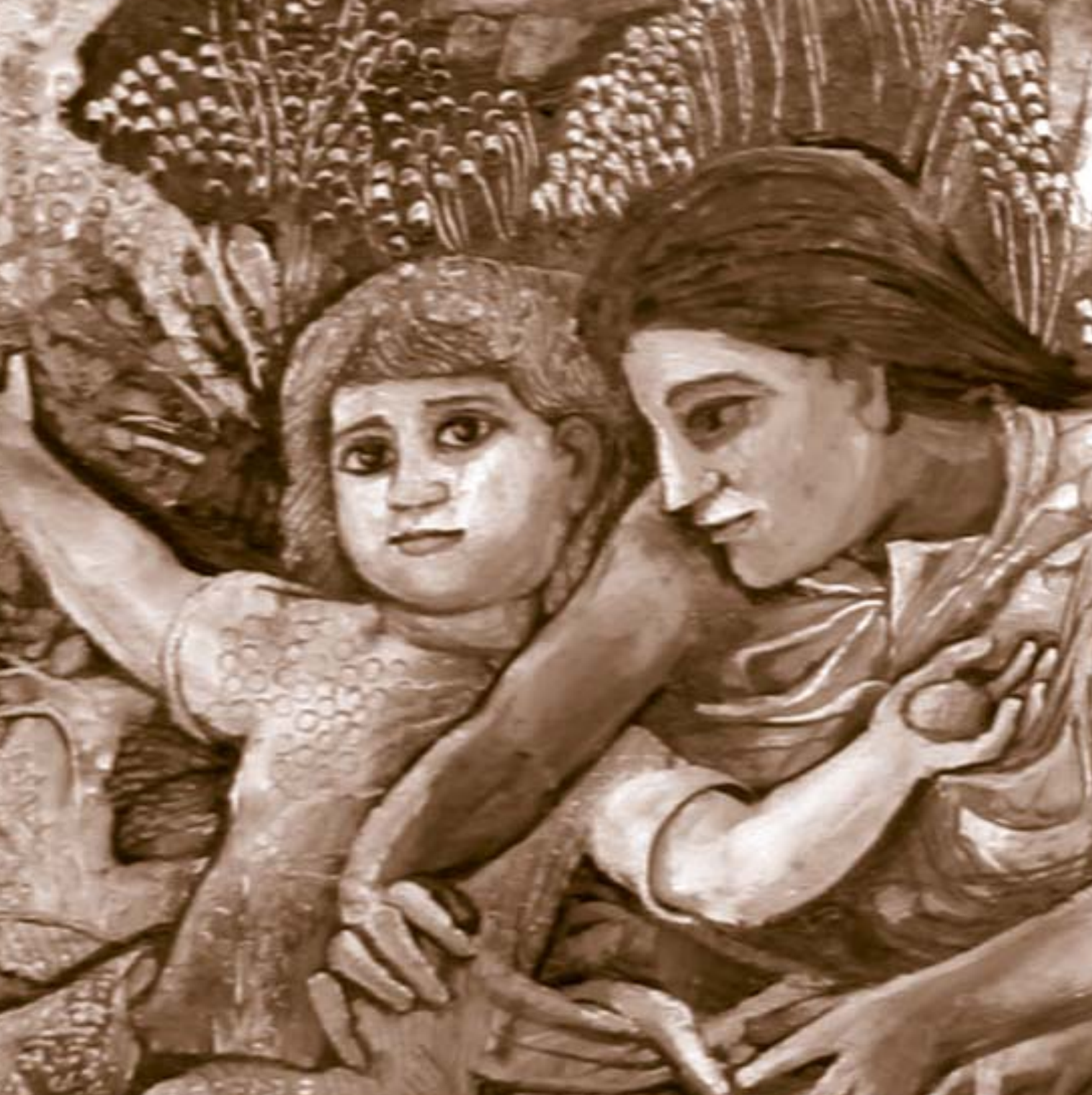

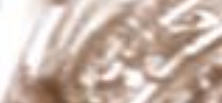

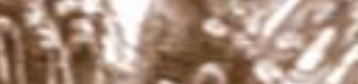

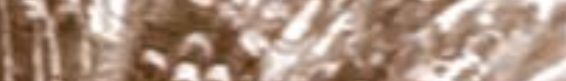

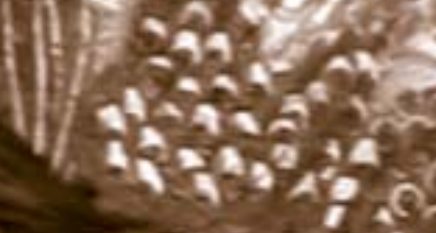

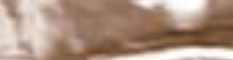
mase

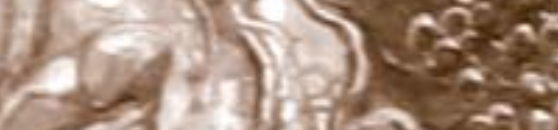

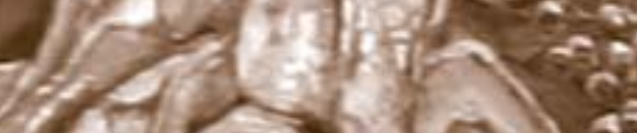




\section{8 a 10 años de la Honduras de hoy y la Honduras del mañana}

Elsa Lily Caballero Z.

En 1995 SECPLA N, Secretaría del A mbiente, M inisterio de Salud Pública, Secretaria de Recursos N aturales, A SH O N PLA FA y USA ID, publicaron el artículo "La $\mathrm{H}$ onduras de $\mathrm{H}$ oy y la $\mathrm{H}$ onduras del M añana", centrándose la discusión en el análisis del impacto del crecimiento de la población en las áreas de salud, educación, economía empleo, medio ambiente, recursos naturales, urbanización y población. En él se relevaba el problema de que el país estuviera entre los de mayor crecimiento a nivel mundial.

Entre sus conclusiones se hace ver la importancia de que el pueblo hondureño y sus líderes reconocieran sus capacidades para aliviar la pobreza, y propiciar el progreso económico y social para alcanzar un desarrollo sostenible. Se reconocía las limitaciones de recursos di sponibles por parte del gobierno y la empresa privada para satisfacer la demanda acelerada de empleos, educación, sal ud y producción y como la tasa de crecimiento poblacional en 1995 no permitiría asumir los retos del desempleo, la delincuencia, la violencia, la deforestación, la deman da de gran os básicos, de agua, de electricidad, y la degradación del medio ambiente.

Después de 10 años del análisis referido, las conclusiones allí plateadas siguen teniendo una enorme vigencia. Los problemas en ese entonces proyectados no solo se mantienen sino que se han agravado.

En la actualidad, $H$ onduras sigue siendo uno de los países con mayor crecimiento a nivel mundial, a pesar de los logros en la disminución de la Tasa de C recimiento, 2.8\% en 1995 y 2.5\% en el 2005, también está catalogado entre los países con mayores problemas de equidad del continente, en el Informe de Desarrollo Humano del PN U D desde 1998 se viene reiterando que el problema más grave y donde menos logros se han obtenido es en la redistribución, determinante fundamental en Ios IDH.

El 29 de marzo del 2005 el FM reconoce que H onduras ha cumplido con las condiciones para ser calificado para la iniciativa H IPI. Ello supone que no solo no se logró reducir la pobreza sino que esta se agudizó a un grado tal que el país ha caído en el compartimiento de los países pobres altamente endeudados, si bien es cierto, ello da el alivio de la carga del pago de la deuda a los acreedores y destinar esos recursos para cubrir los costos de la estrategia de reducción de la pobreza, esta condición hace que $\mathrm{H}$ onduras quede por fuera de iniciativas económicas de inversión para el desarrollo, se supone que en los próximos 10 años tendremos que cumplir con la ERP y las
M etas del Milenio para salir de esa categoría de pobres altamente endeudados y volver a ser un país como los demás.

Es indudable la necesidad que tiene $H$ onduras de hacer uso de estos instrumentos para salir de la pobreza, sin esas iniciativas internacionales para países como el nuestro, es muy seguro que por muchas décadas más, las conclusiones del año 1995 sigan teniendo vigencia, como las tiene en la H onduras de hoy del 2005.

Por ello creemos importante ubicar la condición del país respecto de los retos de la pobreza y desarrollo, para ello usaremos un modelo de representación del escenario actual y futuro, en la idea de ubicarnos en la perspectiva de país.

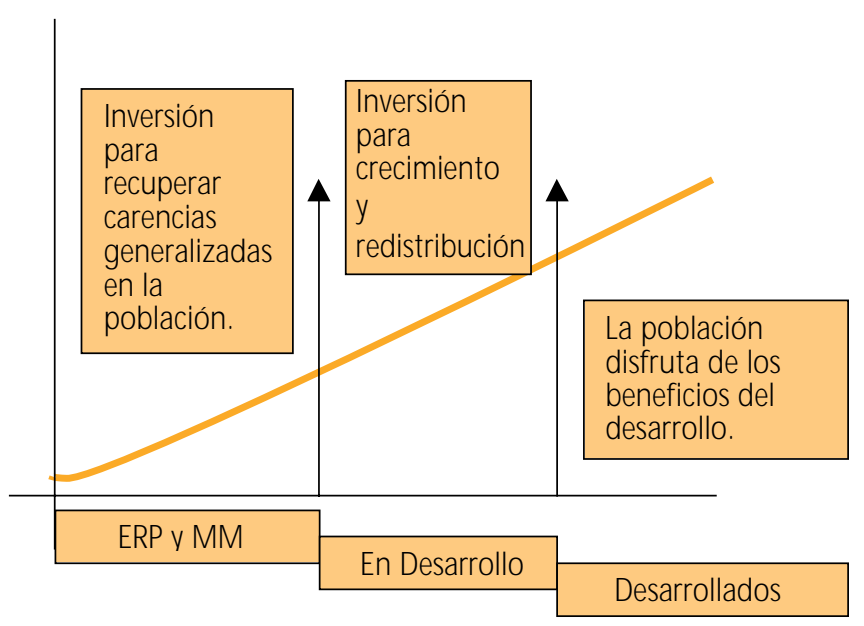

En un modelo simple de representación del escenario actual, $H$ onduras se encuentra ya no en la etapa de despegue económico como se calificó en la década de los 50 del siglo pasado, de acuerdo a la teoría desarrollista, sino que estamos una etapa anterior, país pobre altamente endeudado.

Se supone que al 2015 debemos estar en un estatus diferente al actual, haciendo uso del lenguaje desarrollista, en 10 años debemos alcanzar el estadio de país en desarrollo para que finalmente seamos un país desarrollado.

A unque la práctica ha demostrado que los países no evolucionan de un estadio a otro de manera lineal tal y como se argumentó en las teorías del desarrollo de los años 50, el símil del modelo, con el agregado de una etapa anterior a la denominada "países en desa- 
rrollo" nos permite gráficamente ubicarnos en un estadio inferior en relación a la calificación que nos dieron en los años 50.

En todo caso lo importante (por lo menos en esta reflexión) no es la calificación que nos den o los parámetros teóricos con los cuales nos cal ifiquen, lo importante es reconocer que no hemos podido llegar a donde se supone que deberíamos estar después de 55 años de inversión en el desarrollo. Este es el punto principal de esta argumentación.

Con la A lianza para el Progreso, los programas de sustitución de importaciones, la reforma agraria, las grandes obras de infraestructura, entre los programas insignes, se supone que deberíamos estar en la categoría de "en desarrollo" y no en "países altamente endeudados".

El riesgo de repetir estas situaciones siguen latentes, a nuestro juicio por tres grandes razones y sobre las cuales se quiere llamar la atención con este artículo:

- Concentrarnos como país solo en la ER P y M M como política social.

- No articular la política económica a los procesos de redistribución.

- Seguir siendo un país que no se inmuta ante la degradación ambiental.

1. Concentrarnos como país solo en la ERP y M M como política social.

Bajo las exigencias de la calificación de país pobre altamente endeudado estamos comprometidos con el cumplimiento de la Estrategia de Reducción de la Pobreza y las M etas del M ilenio. Tarea que se ha venido postergando desde hace mucho tiempo atrás y por ello hoy en día se vuelve un compromiso ya no de comunidad nacional sino ante la comunidad internacional.

Reconociendo la urgencia, necesidad e importancia de estas dos medidas, no se debe cometer el error de reducir la política social a ellas, el país requiere de una política social diferenciada. La primera diferenciación se da en la inversión para revertir la pobreza y la inversión para el desarrollo y bienestar social. La primera es básicamente reparativa, la segunda es, por un lado preventiva para evitar volver a los niveles de pobreza alcanzados y por otro, de proyección del país que se quiere lograr más allá de la recuperación de la pobreza, quedarnos en una política social restringida a la ERP y M M es perder la oportunidad del desarrollo.

La segunda diferenciación está determinada por el reconocimiento e identificación de características y necesidades diferenciadas según edad, sexo, raza, etnia y lugar de residencia. Entre muchas determinantes del fracaso de la política social universalista, precisamente fue la incapacidad de reconocer las diferencias por un falso criterio de estandarización de necesidades. A fortunadamente los avances del conocimiento científico y el reconocimiento práctico de la diferencia abren verdaderas oportunidades para no volver a cometer el error de asumir el enfoque unidimensional de la política social.
2. No articular la política económica a los procesos de redistribución.

No obstante los logros obtenidos en la democracia electoral, que indican el camino recorrido en 35 años de construcción de democracia, el pueblo hondureño reciente que esa democracia no se revierta en participación con equidad, particularmente participación política y económica.

En este punto, el tema es no restringir la participación al acto electoral y no seguir separando la dimensión política de la económica como proceso de participación.

Los abundantes estudios sobre pobreza y ética del desarrollo indican que el problema de la pobreza está determinado por la concentración de la riqueza y la exclusión social y no al revés.

Este es el campo más rezagado del país, por ello se sitúa entre los menos equitativos del continente. El A LCA, los tratados de libre comercio y el programa de competitividad, en sí mismos, no aseguran ni contienen medidas de redistribución, entendida ésta no como política social sino como el derecho de la población a la participación económica, la participación en procesos de inversión productiva y de los beneficios de los procesos de inversión. La otra cara de la democracia, la democracia económica.

Este es el punto clave para sentar bases sólidas para un desarroIlo social sostenido, no esa través de la ERP y de las M etas del M ilenio que se logrará el desarrollo social, éste sólo es posible a través de la redistribución económica. La ERP y M M sólo igualarán el punto mínimo necesario para que la población pueda tener igualdad de oportunidades económicas.

Es la ausencia del enfoque de democracia y redistribución económica lo que ha permitido que la democracia política no sobrepase los límites del momento electoral, obviamente, la separación de la democracia política de la democracia económica está llamada a preservar la inequidad.

3. Seguir siendo un país que no se inmuta ante la degradación ambiental.

La catal ogación de $\mathrm{H}$ onduras como país pobre altamente endeudado se desencadena a partir del Mitch, sin él, más tarde, más temprano hubiéramos Ilegado a esta calificación. El punto es que no se perciben señales del aprendizaje de la lección; a 7 años de la peor catástrofe del último siglo provocada por un fenómeno natural, siguen los incendios forestales, la tala del bosque, el mal uso del agua, basura por doquier, sobredensificación de zonas de riesgo y por no hacer ordenamiento territorial fragilizando y dañando otras áreas.

Infortunadamente este es el talón de A quiles del desarrollo, en estudios de la OEA se ha señalado que por la falta de prevención ante los riesgos natural es o antrópicos en los países en desarrollo se ha tenido que usar importantes masas de recursos en reparar daños cuyas medidas preventivas eran de muy bajo costo.

Esimportante resaltar que en el tema ambiental no es suficiente un enfoque reactivo, obviamente y por la posición geográfica del país es necesario contar con instrumentos y mecanismos de respues- 
ta a emergencias. A nte el problema ambiental es necesario reconsiderar dos posturas, una es la de la prevención en la idea de heredar a las generaciones futuras condiciones ambientales saludables y con riesgos minimizados, la otra, consiste en el reconocimiento de que la pobreza y la degradación ambiental no solo son un freno al desarrollo socioeconómico sino que terminan por afectar los procesos de crecimiento económico.

Contar con un documento de referencia de 10 años atrás, nos ayuda a ver hacia el futuro, 10 años después. La idea principal que interesa recuperar consiste en que la $\mathrm{H}$ onduras del mañana no necesariamente tiene que ser una proyección de la $\mathrm{H}$ onduras de hoy, esa ha sido la intención de los diferentes artículos e investigaciones que en épocas diferentes se han escrito sobre nuestro país. Este es el mensaje central que se quiere dejar al recuperar las conclusiones con las que se inició este artículo, bajo la convicción de que es posible una $\mathrm{H}$ onduras redistributiva e incluyente. 